\title{
Perturbation of adhesion molecule-mediated chondrocyte-matrix interactions by 4-hydroxynonenal binding: implication in osteoarthritis pathogenesis
}

Rana El-Bikai, Mélanie Welman, Yoran Margaron, Jean-François Côté, Luke Macqueen, Michael D Buschmann, Hassan Fahmi, Qin Shi, Karim Maghni, Julio C Fernandes, Mohamed Benderdour*

\begin{abstract}
Introduction: Objectives were to investigate whether interactions between human osteoarthritic chondrocytes and 4-hydroxynonenal (HNE)-modified type II collagen (Col II) affect cell phenotype and functions and to determine the protective role of carnosine (CAR) treatment in preventing these effects.

Methods: Human Col II was treated with HNE at different molar ratios (MR) (1:20 to 1:200; Col II:HNE). Articular chondrocytes were seeded in HNE/Col II adduct-coated plates and incubated for 48 hours. Cell morphology was studied by phase-contrast and confocal microscopy. Adhesion molecules such as intercellular adhesion molecule-1 (ICAM-1) and $\alpha 1 \beta 1$ integrin at protein and mRNA levels were quantified by Western blotting, flow cytometry and real-time reverse transcription-polymerase chain reaction. Cell death, caspases activity, prostaglandin E2 $\left(\mathrm{PGE}_{2}\right)$, metalloproteinase-13 (MMP-13), mitogen-activated protein kinases (MAPKs) and nuclear factor-kappa B (NF- $\kappa$ B) were assessed by commercial kits. Col II, cyclooxygenase-2 (COX-2), MAPK, NF- $\kappa$ B-p65 levels were analyzed by Western blotting. The formation of $\alpha 1 \beta 1$ integrin-focal adhesion kinase (FAK) complex was revealed by immunoprecipitation.
\end{abstract}

Results: Col II modification by HNE at MR approximately 1:20, strongly induced ICAM-1, $\alpha 1 \beta 1$ integrin and MMP-13 expression as well as extracellular signal-regulated kinases 1 and $2\left(\right.$ ERK $\left.^{1 / 2}\right)$ and NF- $\kappa \mathrm{B}-\mathrm{p} 65$ phosphorylation without impacting cell adhesion and viability or Col II expression. However, Col II modification with HNE at MR approximately 1:200, altered chondrocyte adhesion by evoking cell death and caspase-3 activity. It inhibited $\alpha 1 \beta 1$ integrin and $\mathrm{Col} \| \mathrm{I}$ expression as well as ERK ${ }^{1 / 2}$ and NF- $\kappa \mathrm{B}-$ p65 phosphorylation, but, in contrast, markedly elicited $\mathrm{PGE}_{2}$ release, COX-2 expression and p38 MAPK phosphorylation. Immunoprecipitation assay revealed the involvement of FAK in cell-matrix interactions through the formation of $\alpha 1 \beta 1$ integrin-FAK complex. Moreover, the modification of Col II by HNE at a 1:20 or approximately 1:200 MR affects parameters of the cell shape. All these effects were prevented by CAR, an HNE-trapping drug.

Conclusions: Our novel findings indicate that HNE-binding to Col II results in multiple abnormalities of chondrocyte phenotype and function, suggesting its contribution in osteoarthritis development. CAR was shown to be an efficient HNE-snaring agent capable of counteracting these outcomes.

\footnotetext{
* Correspondence: mohamed.benderdour@umontreal.ca Orthopaedic Research Laboratory, Hôpital du Sacré-Coeur de Montréal and Department of Surgery, University of Montreal, 5400 Gouin Blvd. West, Montreal, QC H4J 1C5, Canada
} 


\section{Introduction}

Articular cartilage is composed of chondrocytes embedded in an exquisitely-organized extracellular matrix (ECM) of collagen and proteoglycans. Chondrocytes, responsible for regenerating and maintaining cartilage, exist in a relatively-isolated environment, since this tissue lacks blood vessels, lymphatic structures and nerves [1]. The ECM is an important pleiotropic regulator of several fundamental cellular processes, such as migration, proliferation, and phenotypic expression [2]. Chondrocyte phenotype and function are partially controlled by their interactions with the surrounding ECM. These regulatory effects of ECM are mediated through cell surface "adhesion receptors" that support the attachment of cells to ECM molecules both in vivo and in vitro. At the cell surface, matrix receptors link the ECM to the cell interior through elements of the cytoskeleton and other component proteins of signal transduction pathways. In chondrocytes, the bestdescribed families of cell surface receptors are the integrins as well as non-integrin receptors, including CD44 of the hyaluronan-binding protein family, annexin $\mathrm{V}$, and intercellular adhesion molecule-1 (ICAM-1) [3,4]. Integrin attachment stimulates the formation of focal adhesion complexes, intracellular protein complexes that transduce signals from the ECM to intracellular effectors, such as the cytoskeleton [5]. Such receptors convey information from the ECM to the intracellular compartment, utilizing several signal transduction pathways. The binding of matrix components to cell surface receptors also establishes a pericellular pool of ECM molecules that may stabilize cell phenotype.

Osteoarthritis (OA), a chronic disorder affecting the elderly, is characterized by joint pain and disability. Deterioration of articular cartilage is a hallmark of OA pathogenesis [6]. Although the precise aetiology of this disease is still unknown, it is clear that the degradation of articular cartilage is mediated by various factors, such as the production of metalloproteinases (MMPs) and other products resulting from cellular activity that selectively impact the cartilage matrix $[7,8]$. Among them, lipid peroxidation (LPO) end-products, such as 4-hydroxynonenal (HNE) and malondialdehyde (MDA), are believed to play key roles in cartilage damage in OA [9]. Our previous study demonstrated, for the first time, that HNE level was significantly higher in synovial fluids and osteoblasts from OA patients than in normal subjects. We also reported that free HNE was capable of inducing catabolic and inflammatory responses in isolated OA chondrocytes and altering the cellular phenotype of OA osteoblasts. These responses were mediated by the modulation of a panoply of signalling pathways, including mitogen-activated protein kinases (MAPKs) and nuclear factor-kappa B (NF- $\kappa$ B) [10-12]. Generally, free HNE most likely represents one of the main LPO products that can modulate physiological as well as pathological processes, as depicted in a recent, dedicated review [13].

Furthermore, the relevance of LPO products to OA pathogenesis was manifested by their ability to form adducts. By binding to proteins, HNE is capable of activating MMP-13 and increasing the susceptibility of type II collagen (Col II) to proteolytic cleavage by MMP-13 [10]. The formation of HNE/Col II was augmented in human cartilage treated with tumour necrosis factoralpha (TNF $\alpha$ and free radical donors. Tiku et al. reported that chondrocyte-derived LPO products mediate the oxidation of cartilage collagens [14]. They proposed that oxidative modification of cartilage collagen by aldehyde in vivo could result in alteration of the biochemical and biophysical properties of cartilage collagen fibrils, making them prone to degradation and initiating the changes observed in aging and OA.

The present study was undertaken to clarify the significance of high levels of HNE-Col II adducts in OA cartilage. We established that interactions between $\mathrm{OA}$ chondrocytes and HNE-modified ECM protein (for example, Col II) induced changes in cell phenotype and function, consequently contributing to cartilage damage seen during OA development. The beneficial effect of carnosine (CAR), an HNE-trapping drug, was also investigated.

\section{Materials and methods}

\section{Specimen selection and chondrocyte culture}

Post-surgery discarded human OA articular cartilage was obtained from OA patients (aged $67 \pm 9$ years mean \pm $\mathrm{SD}, n=27$ ) who underwent total knee arthroplasty. Informed consent had been obtained from patients with $\mathrm{OA}$ for the use of their tissues for research purposes. All patients were evaluated by rheumatologists who followed American College of Rheumatology criteria [15]. The experimental protocols and use of human tissues were approved by the Research Ethics Board of Hôpital du Sacré-Cœur de Montréal.

OA knee cartilage specimens were spliced and rinsed, and chondrocytes were extracted by sequential enzymatic digestion, as described previously [10]. Cartilage samples were digested with $1 \mathrm{mg} / \mathrm{ml}$ of pronase (Sigma-Aldrich, Oakville, ON, Canada) for one hour at $37^{\circ} \mathrm{C}$, followed by $2 \mathrm{mg} / \mathrm{ml}$ of type IV collagenase (Sigma-Aldrich) for six hours in Dulbecco's modified Eagle's medium (Invitrogen, Burlington, ON, Canada) supplemented with $10 \%$ heat-inactivated fetal bovine serum (FBS, Invitrogen), $100 \mathrm{units} / \mathrm{ml}$ of penicillin and $100 \mu \mathrm{g} / \mathrm{ml}$ of streptomycin (Invitrogen). The cells were seeded at high density in culture flasks at $37^{\circ} \mathrm{C}$ in a humidified atmosphere of $5 \%$ $\mathrm{CO}_{2} / 95 \%$ air until they were confluent and ready for experimentation. 


\section{Plate coating and cell seeding}

Human Col II (Sigma-Aldrich) was modified with HNE (Cayman Chemical Company, Ann Arbor, Ml, USA) at different molar ratios (MR) (1:20 to 1:200; Col II:HNE). 24-well plates (for cell suspensions) were coated with $0.1 \mathrm{mg} / \mathrm{ml} \mathrm{HNE}$-Col II adducts and incubated for $24 \mathrm{~h}$ at $4^{\circ} \mathrm{C}$. They were washed three times with phosphatebuffered saline (PBS) to eliminate free HNE and conserved at $4^{\circ} \mathrm{C}$ until used. First-passage chondrocytes were distributed into pre-treated 24-well plates, as outlined above, at concentrations of $2 \times 10^{5} \mathrm{cells} / \mathrm{cm}^{2}$ in $1 \mathrm{ml}$ in DMEM containing 2\% FBS, and incubated at $37^{\circ} \mathrm{C}$ for $48 \mathrm{~h}$ in a humidified atmosphere containing $5 \%$ $\mathrm{CO}_{2} / 95 \%$ air.

\section{Cell morphology and viability}

Changes in cell morphology were studied by phase-contrast microscopy with a $\times 20 / 40$ objective after hematoxylin and eosin staining $(n=5)$. Chondrocyte viability was evaluated as described previously [16] using 3-(4,5dimethyl-thiazoyl)-2,5-diphenyl-SH-tetrazolium bromide (MTT) assay in 96-well plates (Fisher Scientific Company, Ottawa, ON, Canada) by incubating them with $0.5 \mathrm{mg} / \mathrm{ml} \mathrm{MTT} \mathrm{reagent} \mathrm{(Sigma-Aldrich)} \mathrm{for} 15$ minutes at $37^{\circ} \mathrm{C}$. Then, $100 \mu \mathrm{L}$ of solubilization solution $(0.04 \mathrm{M}$ $\mathrm{HCl}$-isopropanol) was added, formazan salt was dissolved, and absorbance was read at $570 \mathrm{~nm}$ with the micro-ELISA Vmax photometer (Bio-Tek Instruments, Winooski, VT, USA).

\section{Cell spreading assays}

Chondrocytes were grown for $48 \mathrm{~h}$ in eight-well LabTeck chambers $\left(2 \times 10^{5}\right.$ cells $\left./ \mathrm{cm}^{2}\right)$ coated with $0.1 \mathrm{mg} / \mathrm{ml}$ HNE-Col II adducts. Cells were fixed by $4 \%$ paraformaldehyde for 30 minutes. An immunofluorescence was performed and the areas, perimeters, Feret's diameters and circularity index of more than 200 cells were analyzed using the threshold function of Image-J software (NIH) ( $n=4$ for each condition).

\section{Immunofluorescence}

Cells were fixed with $4 \%$ paraformaldehyde, permeabilized with $0.2 \%$ Triton X-100 (Sigma-Aldrich) in PBS and blocked in PBS-1\% BSA (United States Biological, Swampscott, MA, USA), and then incubated with Alexa Fluor 488 Phalloidin (1:200 dilution, Invitrogen) for 30 minutes. After one wash in Tween $0.2 \%$ (Sigma-Aldrich) in PBS and three in PBS alone, the chambers slides were mounted with coverslips using Slow Fade Gold antifade reagent with DAPI mounting medium (Invitrogen). Fluorescence images were captured with a Zeiss LSM710 confocal microscope, and the quantitative cell morphology analysis was performed using images taken with a Leica DM6000 epifluorescence microscope
(Deerfield, IL, USA) equipped with a Retiga EXi (QImaging, Burnaby, BC, Canada) camera $(n=4)$.

\section{Immunoprecipitation}

To demonstrate the involvement of FAK in cell-collagen interaction, OA chondrocytes (approximately $10^{6}$ cells, $n=3$ ) were incubated for $48 \mathrm{~h}$ in HNE/Col II adductscoated plates. Then, cells were lysed on ice in $1 \mathrm{ml}$ lysis buffer (KLB: $40 \mathrm{mM}$ Tris (pH 8.0), $250 \mathrm{mM} \mathrm{NaCl}, 0.1 \%$ Nonidet P-40, $5 \mathrm{mM}$ EDTA, $5 \mathrm{mM}$ EGTA, $10 \mathrm{mM}$ $\beta$-glycerophosphate, $10 \mathrm{mM} \mathrm{NaF}, 0.3 \mathrm{mM} \mathrm{Na}_{3} \mathrm{VO}_{4}$, $1 \mathrm{mM}$ DTT) supplemented with protease inhibitors cocktail as described previously [11]. A total of $100 \mu \mathrm{g}$ of total protein was subjected to immunoprecipitation with $1 \mu \mathrm{g}$ of mouse anti-human $\alpha 1 \beta 1$ integrin (Santa Cruz Biotechnology, Santa Cruz, CA, USA) in KLB buffer containing $0.5 \mathrm{M} \mathrm{NaCl}$ for overnight at $4^{\circ} \mathrm{C}$ and then for an additional two hours with protein A (Santa Cruz Biotechnology). The resin was washed with KLB buffer and proteins were removed from the resin by the addition of $50 \mu \mathrm{l}$ undiluted SDS-loading buffer. The immunoprecipitates were analyzed by Western blotting using mouse anti-human $\alpha 1 \beta 1$ integrin (Santa Cruz Biotechnology) or rabbit anti-pFAK antibody (Millipore, Etobicoke, ON, Canada), as primary antibody.

\section{Measurement of caspase activities}

Enzymatic caspase-3/8 activities were measured with commercial kits. To measure caspase- 8 activity, the cells $(n=5)$ were washed with PBS and resuspended in $100 \mu \mathrm{L}$ of lysis buffer (R\&D Systems, Minneapolis, MN, USA), left on ice for 10 minutes, and centrifuged. Protein concentration of the supernatants was measured according to the bicinchoninic acid method (Pierce, Rockford, IL, USA). Total proteins $(50 \mu \mathrm{g})$ were reacted with $200 \mu \mathrm{M}$ IETD- $p$ NA substrate in the presence of $100 \mu \mathrm{L}$ of reaction buffer. To quantitate caspase- 3 activity, the cells were washed with PBS and lysed in $100 \mu \mathrm{L}$ of lysis buffer (Sigma-Aldrich), left on ice for $15 \mathrm{~min}$ utes, and centrifuged. Total proteins $(5 \mu \mathrm{g})$ were reacted with $200 \mu \mathrm{M}$ DEVD- $p$ NA substrate in the presence of $100 \mu \mathrm{L}$ of reaction buffer. After 16 hours of incubation at $37^{\circ} \mathrm{C}, p$-nitroanilide release was measured at $405 \mathrm{~nm}$ for caspase- 3 and -8 .

\section{Protein detection by Western blotting}

A sum of $20 \mu \mathrm{g}$ of total proteins from chondrocyte lysates $(n=4)$ treated under the indicated conditions was loaded for discontinuous 4 to $12 \%$ sodium dodecyl sulfate-polyacrylamide gel electrophoresis. They were then transferred electrophoretically onto nitrocellulose membranes (Bio-Rad Laboratories, Mississauga, ON, Canada) for protein immunodetection and semi-quantitative measurement [10]. The primary antibodies used were mouse 
anti-human ICAM-1, anti-human $\alpha 1 \beta 1$ integrin and anti-human $\beta$-actin (Santa Cruz Biotechnology), anti-Col II (Oncogene Research Products, La Jolla, CA, USA) or rabbit anti-human COX-2 (Cayman Chemical Company), anti-pFAK (Millipore), anti-total and phosphorylated extracellular signal-regulated kinases 1 and $2\left(E^{2} K^{1 / 2}\right)$, p38 MAPK, and NF- $\kappa$ B-p65 (Cell Signaling Technology, Inc., Danvers, MA, USA). After serial washes, the primary antibodies were revealed by goat anti-mouse or antirabbit IgG conjugated to horseradish peroxidase (Cell Signaling Technology). Immunoreactive proteins were detected with SuperSignal blotting substrate (Pierce) and exposed to Kodak X-Omat film (Eastman Kodak Company, Rochester, NY, USA).

\section{Prostaglandin E2 $\left(\mathrm{PGE}_{2}\right)$ and MMP-13 determination}

After incubating the chondrocytes for $48 \mathrm{~h}$ in collagencoated plates, the medium was collected, and $\mathrm{PGE}_{2}$ and MMP-13 levels were assessed by enzyme immunoassay (Cayman Chemical Company) and ELISA kits (R\&D Systems). Detection sensitivity was 9 and $8 \mathrm{pg} / \mathrm{ml}$, respectively. All assays were performed in duplicate $(n=$ 6). Absorbance was measured with the micro-ELISA Vmax photometer (Bio-Tek Instruments).

\section{RNA extraction and reverse transcription-polymerase chain reaction (RT-PCR)}

Total RNA was isolated with TRIzol reagent according to the manufacturer's instructions (Invitrogen). RNA was quantitated with RiboGreen RNA quantitation kits (Molecular Probes, Eugene, OR, USA), dissolved in diethylpyrocarbonate-treated $\mathrm{H}_{2} \mathrm{O}$, and stored at $-80^{\circ} \mathrm{C}$ until used. One $\mu \mathrm{g}$ of total RNA was reverse-transcribed with Moloney murine leukemia virus reverse transcriptase (Fermentas, Burlington, ON, Canada), as detailed in the manufacturer's guidelines. One-fiftieth of the reverse transcriptase reaction product was analyzed by real-time quantitative PCR. The following specific sense and antisense primers were purchased from Bio-Corp Inc. (Montreal, QC, Canada): human ICAM-1, 5'-CCT ATG GCA ACG ACT CCT TC-3' (forward) and 5'-TGC GGT CAC ACT GAC TGA G-3' (reverse); human $\alpha 1$ integrin, 5'-GGA GCA ATT CGA CGA GCA CT-3' (forward) and 5'-TTC ATC CCG CAG ATA CGC TA-3' (reverse); human $\beta 1$ integrin, 5'-TTC AAT GCC ACC TGC CTC AA-3' (forward) and 5'-TTG GCC TCA ATG CTG AAG CTC-3' (reverse); human GAPDH, 5'-CAG AAC ATC ATC CCT GCC TCT-3' (forward) and 5'GCT TGA CAA AGT GGT CGT TGA G-3' (reverse); human MMP-13, 5'-CTT AGA GGT GAC TGG CAA AC (forward) and 5'-GCC CAT CAA ATG GGT AGA AG (reverse); human COX-2, 5'-TTC AAA TGA GAT TGT GGG AAA ATT GCT-3' (forward) and 5'-AGT TCA TCT CTG CCT GAG TAT CTT-3' (reverse).
Quantitative PCR analysis was performed in a total volume of $50 \mu \mathrm{l}$ containing template DNA, $200 \mathrm{nM}$ sense and antisense primers, $25 \mu \mathrm{l}$ of SYBR Green Master Mix (Qiagen, Mississauga, Ontario, Canada), and 0.5 units of uracil- $\mathrm{N}$-glycosylase (UNG, Epicentre Technologies, Madison, WI, USA). After incubation at $50^{\circ} \mathrm{C}$ for two minutes (UNG reaction) and at $95^{\circ} \mathrm{C}$ for 10 minutes (UNG inactivation and activation of AmpliTaq Gold enzyme), the mixtures were subjected to 40 amplification cycles $\left(15 \mathrm{~s}\right.$ at $95^{\circ} \mathrm{C}$ for denaturation and one minute at $60^{\circ} \mathrm{C}$ for annealing and extension). Incorporation of SYBR Green dye into the PCR products was monitored in real-time with a Mx3000 real-time PCR system (Stratagen, La Jolla, CA, USA), allowing determination of the threshold cycle $\left(\mathrm{C}_{t}\right)$ at which exponential amplification of PCR products begins. After PCR, dissociation curves were generated with one peak, indicating amplification specificity. A $C_{t}$ value was obtained from each amplification curve with software provided by the manufacturer (Stratagen).

Relative mRNA expression in chondrocytes was quantified according to the $\Delta \Delta \mathrm{C}_{\mathrm{t}}$ method, as detailed in the manufacturer's (Stratagen's) guidelines. A $\Delta \mathrm{C}_{\mathrm{t}}$ value was calculated, first by subtracting the $C_{t}$ value for the housekeeping gene GAPDH from the $\mathrm{C}_{\mathrm{t}}$ value for each sample. A $\Delta \Delta C_{t}$ value was then calculated by subtracting the $\Delta C_{t}$ value for the control (unstimulated cells) from the $\Delta C_{t}$ value for each treatment. Fold changes compared to the controls were then determined by $2^{-\Delta \Delta C}$. Each PCR generated only the expected specific amplicon, as shown by melting temperature profiles of the final product and by gel electrophoresis of the test PCRs. Each PCR was run in triplicate on two separate occasions for each independent experiment $(n=6)$.

\section{Flow cytometric analysis}

Incubated cells in unmodified or HNE-modified Col II were trypsinized, centrifuged and then labeled with either $1 \mu \mathrm{g}$ of a purified mouse $\mathrm{IgG}_{1}$ isotype control (BD Biosciences PharMingen; San Diego, CA, USA), or mouse anti-human ICAM-1 (15.2) (Santa Cruz Biotechnology) in $\mathrm{PBS} / 2 \% \mathrm{FBS}$ for 60 minutes at $4^{\circ} \mathrm{C}$. The cells were then washed twice in PBS and incubated with Alexa Fluor 488 goat anti-mouse IgG (Invitrogen) diluted $1 / 500$ in $\mathrm{PBS} / 2 \% \mathrm{FCS}$, for 30 minutes at $4^{\circ} \mathrm{C}$ in the dark. They were washed, re-suspended in $500 \mu \mathrm{l}$ of PBS and analyzed. ICAM-1 surface expression on chondrocytes $(n=4)$ was assessed in a Coulter Epics XL flow cytometer with Expo32 software (Beckman Coulter System, Mississauga, ON, Canada).

\section{MAPK and NF- $\kappa$ B quantification}

After $48 \mathrm{~h}$ of incubation, human OA chondrocytes $(n=4)$ were lysed, and protein levels were quantitated according 
to the BCA method. The samples were assayed with ELISA kits for total and phosphorylated p38 MAPK, ERK ${ }^{1}$ (p44), ERK ${ }^{2}$ (p42), and NF- $\kappa$ B-p65 (Cell Signaling Technology, Inc.). The data are expressed as fold induction.

\section{Statistical analysis}

Results were expressed as the mean \pm SEM. Statistical differences between two groups of data were analyzed using ANOVA test and Bonferroni's multiple comparison procedures. A difference of less than or equal to 0.05 was considered significant.

\section{Results}

HNE-binding to Coll II induces changes in cell morphology, viability and phenotype

To investigate the effect of HNE-binding to Col II on chondrocyte function, we first documented changes in cell morphology and viability by phase-contrast microscopy and MTT assay, respectively. After $48 \mathrm{~h}$ of incubation, Col II modification by HNE at high MR (1:200) (Figure 1c) induced alterations in cell morphology compared to unmodified Col II or collagen exposed to HNE at low MR (1:20) (Figure 1a, b). The changes in cell morphology were associated with cell viability decreased by $30 \%$ and caspase- 3 activity increased by approximately two-fold respectively (Figure $1 \mathrm{~d}$ ). In the same pattern, caspase- 8 activity was also increased (data not shown). Thereafter, we evaluated the ability of HNEmodified Col II to affect chondrocyte phenotype via Col II protein expression. As illustrated in Figure 1e, Col II protein expression was reduced by 25 and $65 \%$ when the cells were seeded in Coll II treated with HNE at a 1:100 MR and 1:200 MR respectively, indicating altered cell phenotype. Col II modification with HNE up to 1:100 MR did not influence cell viability, and caspase-3 activity. These data indicate that interactions between human OA chondrocytes and HNE-Coll II adduct influence cell morphology, viability and phenotype.

Then, chondrocytes morphology were analysed by measuring main parameters of the cell shape, including: the area, Feret's diameter, perimeter, and circularity index. Figure 2a indicates that culture conditions don't affect cell area. However, Col II modification with HNE at a 1:200 MR significantly decreased the Feret's diameter of cell compared to the control. (Figure 2b), indicating that cells make less straight membrane protrusions. Moreover, cell perimeter is significantly increased when cells were cultured in the presence of HNE-modified Col II at a 1:20 MR compared to the control (Figure 2c), but decreased in the presence of HNE-modified Col II at a 1:200 MR. In the same way, the circularity index of the cells is reduced in the presence of HNE-modified Col II at a 1:20 MR and increased then after in the presence of HNE-modified Col II at a 1:200 MR (Figure 2d). Finally, cells seem to be more spread in unmodified Col II or HNE-modified Col II at a 1:20 MR than in HNE-modified Col II at a 1:200 MR (Figure 2e-g). Taken together, these results indicate that cells are more rounded and smooth when Col II was high alkylated by HNE when compared to unmodified Col II and low alkylated Col II.

\section{HNE-binding to Col II modulates the expression of adhesion molecules (ICAM-1 and $\alpha 1 \beta 1$ integrin)}

Cell adhesion molecules are expressed on the cell surface and are involved in binding with other cells or with the ECM components. They play a critical role in a wide array of biological processes that include differentiation, viability, inflammation and catabolism. In the present study, we investigated both ICAM- 1 and $\alpha 1 \beta 1$ integrin in cultured chondrocytes in HNE-modified Col II-coated plates. Compared to unmodified Col II, Col II modification with HNE at low MR (1:20) induced ICAM-1 expression at the protein (Figure 3a) and mRNA (Figure 3d) levels by $440(P<0.001)$ and $400 \%$ $(P<0.001)$, respectively. No change in ICAM-1 expression was observed when Col II was modified by HNE at a 1:100 or 1:200 MR.

We then undertook flow cytometric analysis to confirm the Western blotting and real-time PCR data. Figure 3C discloses that Col II modification by HNE at a 1:20 MR (Figure 3c.b2) increased the percentage of cells expressing ICAM-1 by two-fold at the surface of chondrocytes, compared to control cells (Figure 3c.b1). When the data were analyzed for X-mean fluorescence intensity, almost a 10-fold increment in ICAM-1 expression was noted (Figure 3c.b2). However, incubated cells with HNEtreated Col II at a 1:200 MR presented ICAM-1 expression levels comparable to those in control cells in terms of both cell percentage and X-mean fluorescence intensity (Figure 3c.b3). Flow cytometry of ICAM-1 expression on chondrocytes in response to their incubation in HNEmodified Col II was in agreement with the Western blotting and real-time PCR data.

Furthermore, $\alpha 1$ and $\beta 1$ integrin expression increased, in the same pattern, by $150(P<0.05)$ and $160 \%(P<0.05)$ at the protein level (Figure 3a) and by $230(P<0.05)$ and $310 \%(P<0.01)$ at the mRNA level (Figure $3 \mathrm{~d})$ when $\mathrm{Col}$ II was modified by HNE at a 1:20 MR. However, Col II modification with HNE at a 1:200 MR dramatically decreased the expression of both $\alpha 1$ and $\beta 1$ integrin by approximately $85 \%(P<0.001)$ at the protein and mRNA levels (Figure 3a, d). Collectively, these data suggest that inhibition of $\alpha 1 \beta 1$ integrin expression will be involved in alterations of chondrocyte morphology, viability and phenotype, as observed in Figure 1.

Coimmunoprecipitation experiments were performed to determine the involvement of FAK in cell-matrix interactions. Our data showed that pFAK is detected in 

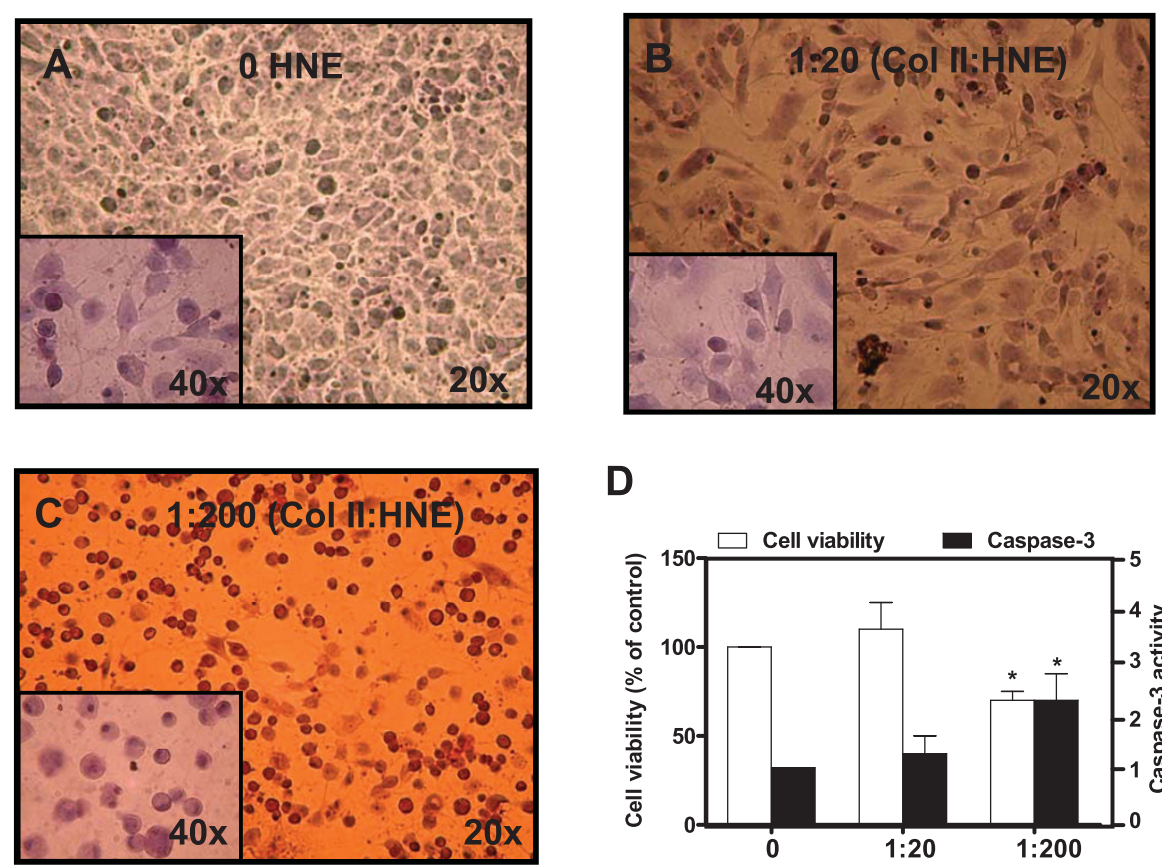

D

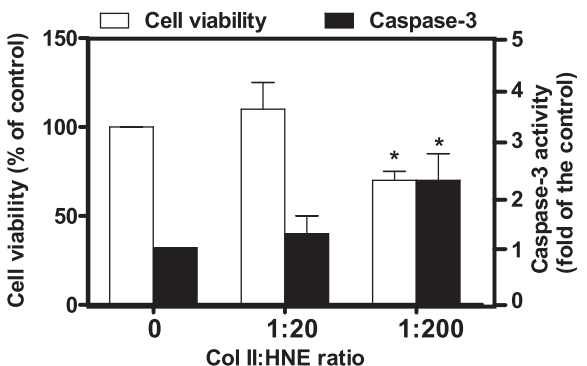

$\mathbf{E}$ Col II:HNE ratio

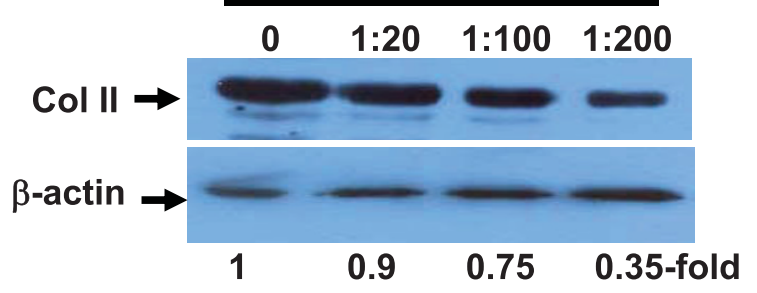

Figure $1 \mathrm{HNE}$-binding to Coll II induces changes in chondrocytes morphology, viability and phenotype. Twenty-four-well plates were coated with $0.1 \mathrm{mg} / \mathrm{ml}$ human Col II and treated after with HNE at different molar ratios (1:20 to 1:200; Col II:HNE). After several washes, human OA chondrocytes were seeded at $2 \times 10^{5}$ cells $/ \mathrm{cm}^{2}$ and incubated up to $48 \mathrm{~h}$. Cell morphology of cultured chondrocytes in untreated Col II (a), HNE-treated Col II at a 1:20 MR (b), and HNE-treated Col II at a 1:200 MR (c) was observed by phase contrast microscopy after hematoxylin and eosin staining (mag. 20 to 40x). (d) Cell viability and caspase-3 activity were determined with MTT assay and commercial kit respectively. (e) Col II protein expression was analyzed in cellular extract by Western blot. ANOVA tests and Bonferroni's multiple comparison were performed to compare each condition. The data are means \pm SEM of $n=5 .{ }^{*} P<0.05 ;{ }^{* *}, P<0.01$.

$\alpha 1 \beta 1$ integrin immunoprecipitates from cultured chondrocytes (Figure 3b). The phosphorylated level of FAK increased when Col II was modified by HNE at a 1:20 MR and then decreased when Col II was modified by HNE at a 1:200 MR.

Interactions between HNE-modified Col II and chondrocytes induce inflammatory and catabolic responses

In the next series of experiments, we investigated whether interactions between chondrocytes and their surrounding matrix, HNE-modified Col II, regulate the production of factors known to be involved in OA, such as $\mathrm{PGE}_{2}$, a product of COX-2, and MMP-13. Our data revealed that $\mathrm{HNE}$-modified $\mathrm{Col} \mathrm{II}$ induced $\mathrm{PGE}_{2}$ release and COX-2 expression. $\mathrm{PGE}_{2}$ (Figure 4a) peaked at 720 $\mathrm{pg} / \mathrm{ml}(P<0.001)$, and COX -2 protein and mRNA (Figure $4 \mathrm{~b}, \mathrm{c})$ reached 480 and $350 \%(P<0.001)$, respectively, when Col II was treated with HNE at a 1:200 MR. We additionally established that HNE-modified Col II evoked a significant increase of MMP-13 but inversely to COX-2. MMP-13 protein and mRNA (Figure $4 \mathrm{~d}$ ) reached maximum levels of $17 \mathrm{ng} / \mathrm{ml}(P<0.001)$ and 400\% $(P<0.001)$, respectively, when Col II was modified with $\mathrm{HNE}$ at a 1:20 MR. Taken together, these findings 

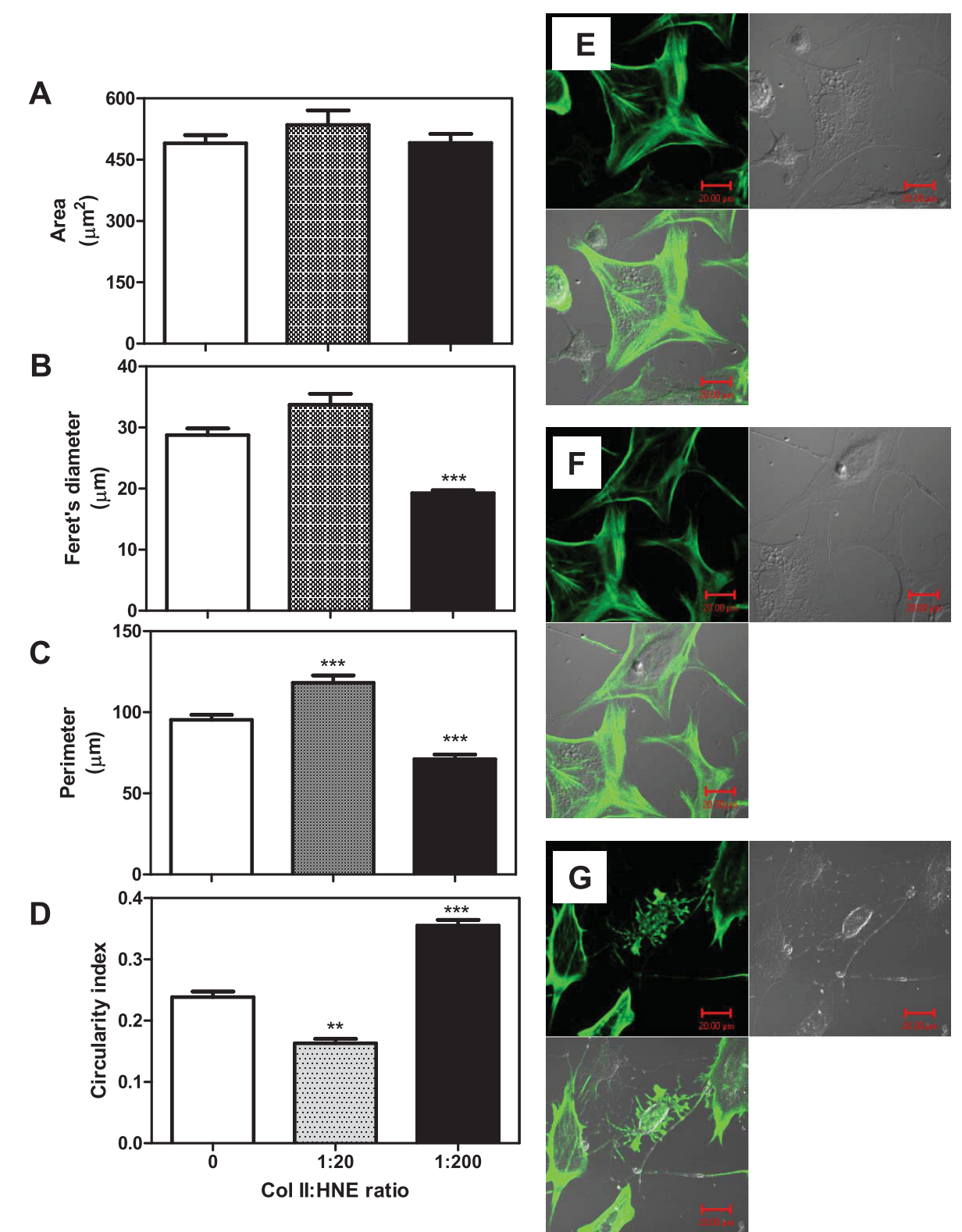

Figure 2 Chondrocyte morphology analysis and actin cytoskeleton. Chondrocytes were incubated as described in Legend 1 and cell morphology was analyzed by fluorescence microscopy using a phalloidin staining and ImageJ analysis. For each condition, the area (a), the Feret's diameter (b), the perimeter (c) and the circularity index (d) of more than 200 cells was measured. Cell cytoskeleton was observed by phalloidin in cultured chondrocytes in untreated Col II (e), HNE-treated Col II at a 1:20 MR (f), and HNE-treated Col II at a 1:200 MR (g). Scale bar, $20 \mu \mathrm{m}$. ANOVA tests and Bonferroni's multiple comparison were performed to compare each condition. The data are means $\pm \operatorname{SEM}$ of $n=4$. ${ }^{* *} P<0.01$; ${ }^{* *} P<0.001$.

suggest that interactions between chondrocytes and HNE-modified Col II may contribute to the production of inflammatory and catabolic mediators known to be involved in OA.

\section{HNE-binding to Col II activates p38 MAPK, ERK ${ }^{1 / 2}$ and NF- $\kappa$ B-p65}

To gain insights into the signalling pathways activated during interactions between chondrocytes and HNE- modified Col II, we examined the HNE-induced phosphorylation patterns of MAPKs over extended time periods by Western blotting and ELISA. As shown in Figure 5a, b, our data indicate that p38 MAPK, ERK ${ }^{1 / 2}$ and NF- $\kappa$ B-p 65 phosphorylation levels rose within $48 \mathrm{~h}$ of stimulation and depended on Col II alkylation level. p38 MAPK activation peaked when Col II was modified by HNE at 1:200 MR (Figure 5a, b.b1). In contrast, ERK ${ }^{1 / 2}$ (Figure 5a, b.b2, b.b3) and NF- $\kappa$ B-p65 (Figure 5a, b.b4) 


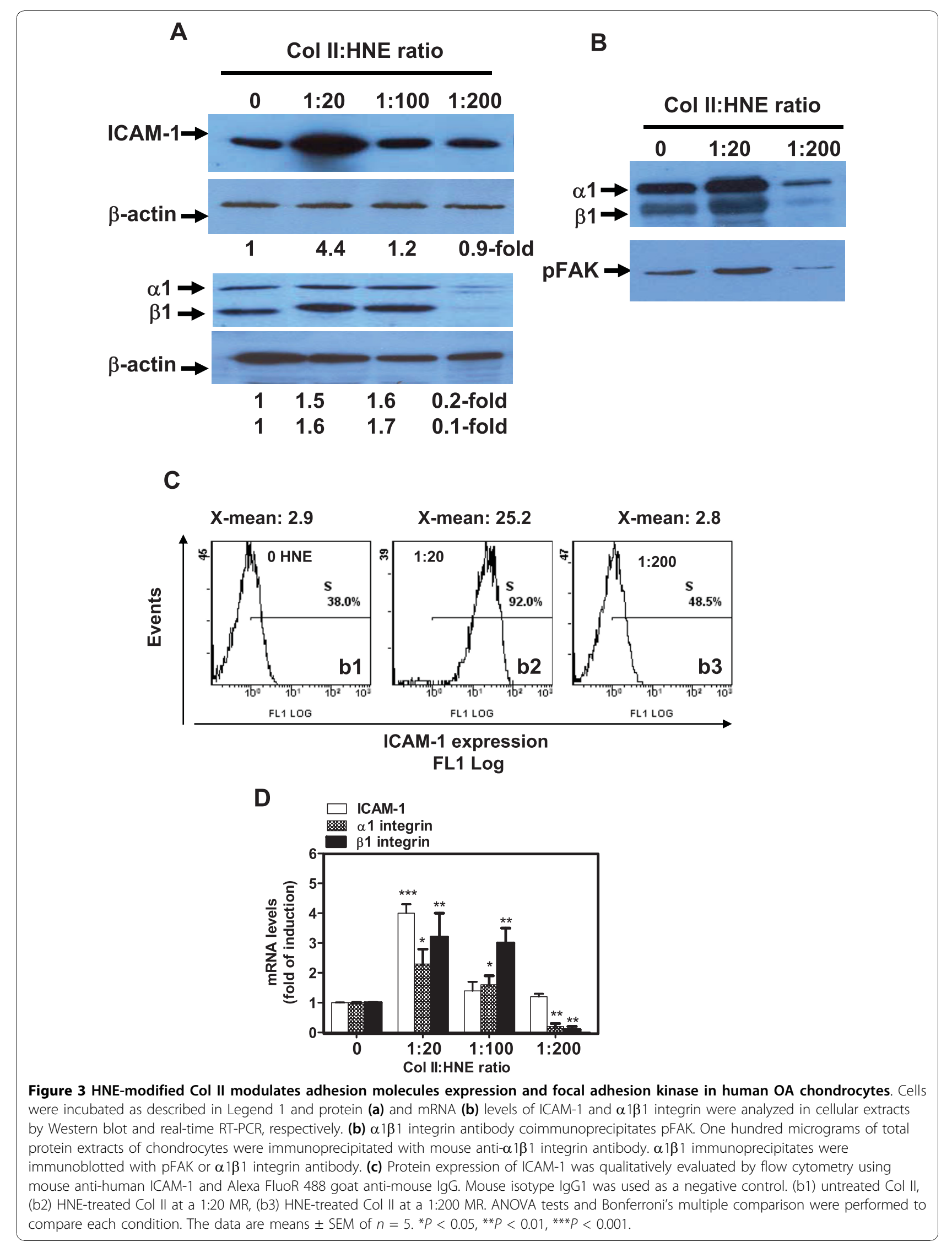




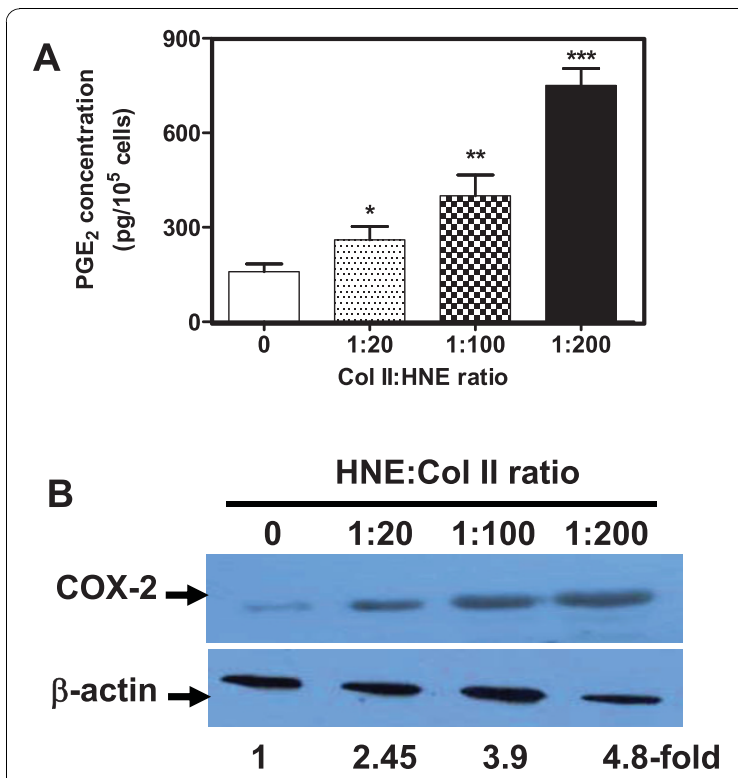

C
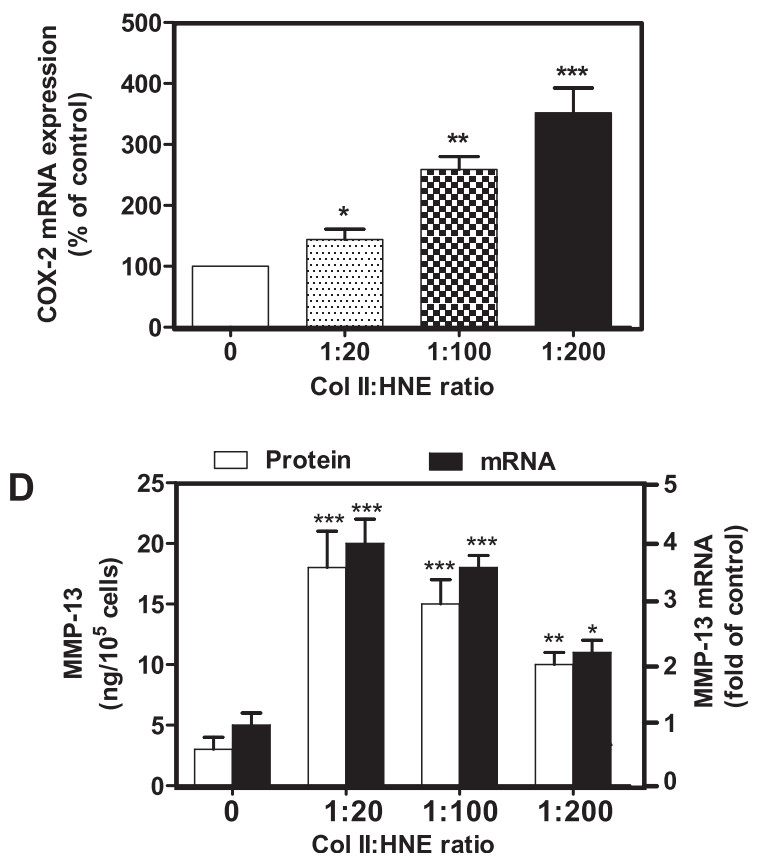

Figure 4 Interactions between human $O A$ chondrocytes and HNE-modified Col II induced COX-2 and MMP-13 expression. Cells were incubated as described in Legend 1 and culture media was collected. PGE 2 (a) and MMP-13 (d) release was assessed by enzyme immunoassay and ELISA kits. Levels of COX-2 protein (b) as well as COX-2 mRNA (c) and MMP-13 mRNA (d) were analyzed in cellular extracts by Western blot and real-time RT-PCR, respectively. ANOVA tests and Bonferroni's multiple comparison were performed to compare each condition. The data are means \pm SEM of $n=6$. ${ }^{*} P$ $<0.05,{ }^{* *} P<0.01,{ }^{* *} P<0.001$.

activation peaked when Col II was exposed to HNE at a 1:20 MR HNE and declined gradually thereafter when Col II was modified by HNE at a 1:100 or 1:200 MR. However, our results disclosed that interactions between cells and HNE-modified Col II evoked weak activation of c-Jun N-terminal kinase $1 / 2\left(\mathrm{JNK}^{1 / 2}\right)$ (data not included).

\section{CAR prevents HNE-modified Col II-induced chondrocyte functions}

To establish whether HNE-modified Col II induced changes in cell morphology and function could be potentially reversed by CAR, an HNE-trapping drug, 0.1 mM CAR was added to HNE-modified, Col II-coated plates one hour before cell seeding, and different factors were investigated. As seen in Figure 6, CAR prevented changes in cell morphology (Figure 6c) when compared to the untreated Col II (Figure 6a) and HNEmodified Col II at a 1:200 MR (Figure 6b). CAR alone had no effect on cell viability (Figure 6d). Interestingly, we observed that cell mortality as well as $\mathrm{PGE}_{2}$ and MMP-13 release were abolished by CAR (Figure 6e, f) when cells were incubated with HNE-modified Col II. These data indicated that CAR prevented changes in chondrocyte phenotype and function by establishing normal interactions between the cells and their surrounding matrix.

\section{Discussion}

The main purpose of this study was to investigate interactions between human OA chondrocytes and HNEmodified Col II. When seeded in HNE-treated Coll II, significant amendment of chondrocyte morphology, from the typical chondrocyte-like polygon shape to rounded, semi-detached cells, was observed; mainly when Col II was modified by HNE at a 1:200 MR (Col II:HNE). Since morphological changes in cell shape are consistent with the induction of cell death, we studied cell viability and extrinsic caspase- 3 activity. Our data disclosed that changes in cell morphology were accompanied by increased cell mortality, caspase- 3 activation and loss of cell phenotype, as determined by Col II expression. Several authors have reported that fibroblast and osteoblast interactions with MDA-collagen adducts or advanced glycation end product (AGE)-modified collagen affected both the morphology and proliferation of these cells, leading to reduced cell adhesion, migration and viability $[17,18]$. It has been proposed that changes in both the physical properties and charge profiles of protein are particularly important for the attachment of cells to collagenous basement membranes. To determine that chondrocyte morphology and phenotype were closely correlated with cell-matrix interactions through adhesion molecules, we first investigated ICAM-1 and $\alpha 1 \beta 1$ integrin expression. Our results clearly showed that interactions between HNE-modified Coll II at a 1:20 MR and chondrocytes, probably through $\alpha 1 \beta 1$ receptors, significantly increased its own expression, and 


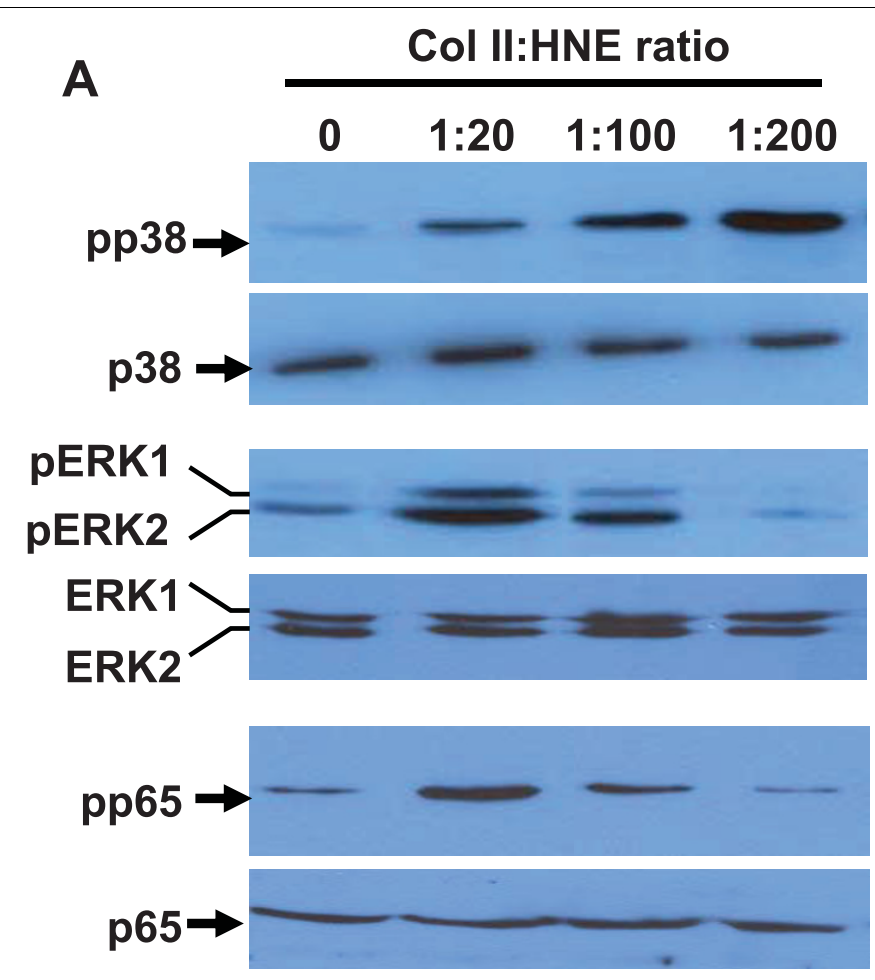

B
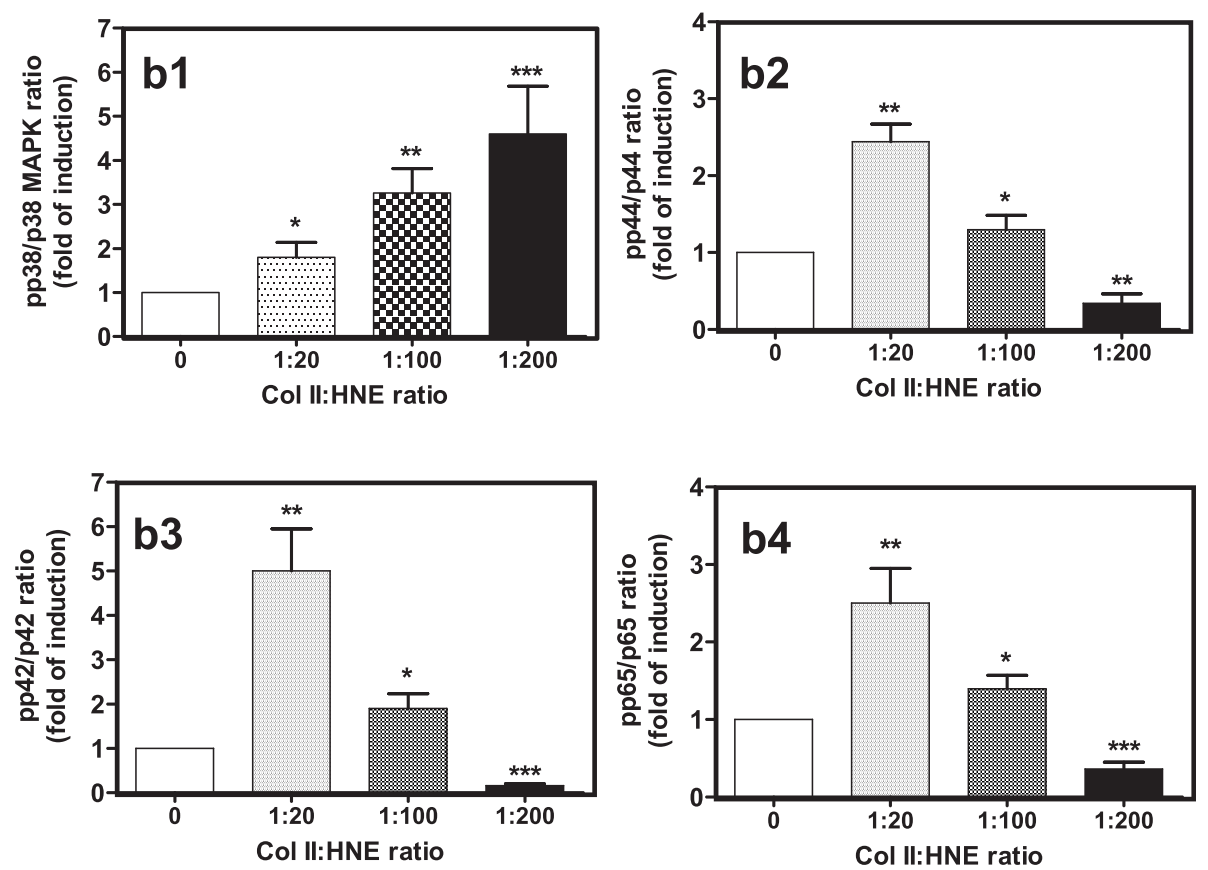

Figure 5 Activation of MAPK and NF- $\kappa$ B pathways by HNE-modified Col II in human OA chondrocytes. Cellular extracts from incubated chondrocytes (see legend 1) were subjected to assess total and phospho-p38 MAPK, ERK ${ }^{1}$ (p44), ERK ${ }^{2}$ (p42) and NF- $\kappa$ B-p65 by (a) Western blot analysis using specific antibodies or by (b) ELISA procedure using commercial kit. (b1) p38 MAPK, (b2) ERK', (b3) ERK², (b4) NF- $\kappa$ B-p65. ANOVA tests and Bonferroni's multiple comparison were performed to compare each condition. The data are means \pm SEM of $n=4 .{ }^{*} P<0.05,{ }^{*} P<0.01,{ }^{* * *} P<0.001$. 

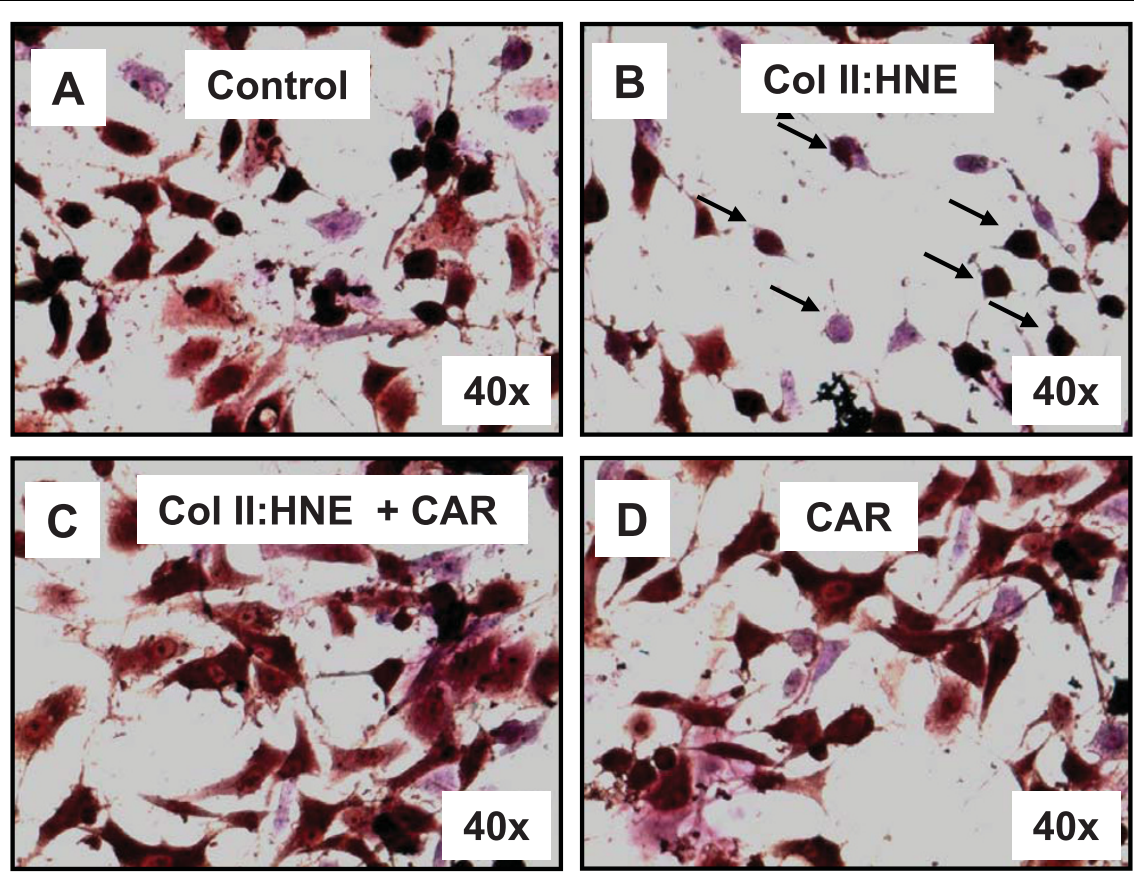

E

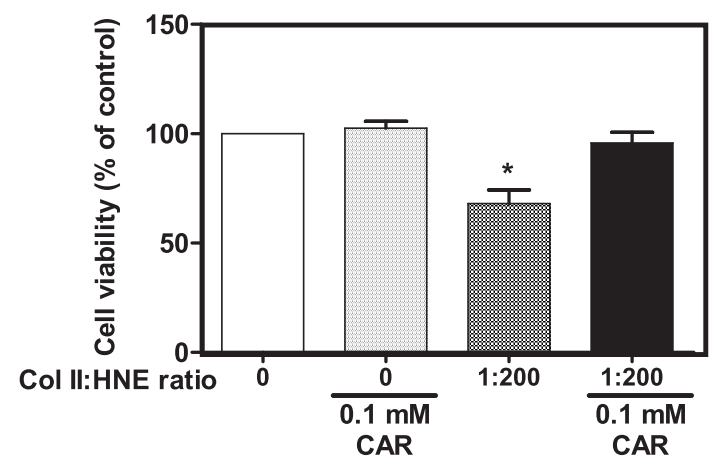

$\mathbf{F}$

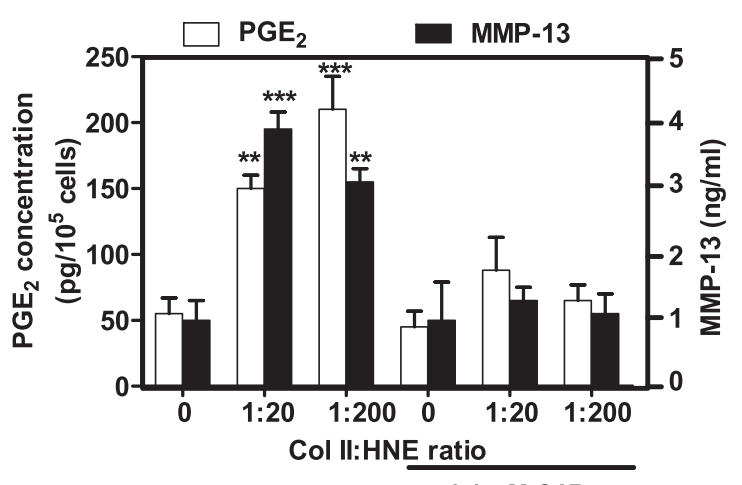

$0.1 \mathrm{mM}$ CAR

Figure 6 Carnosine prevents HNE-modified Coll II-induced changes in chondrocytes phenotype and function. A total of $0.1 \mathrm{mM}$ carnosine was added to HNE-modified Col II-coated plates before cells seeding. Cell morphology of human OA chondrocytes was analysed by phase-contrast microscopy. Cells were incubated in (a) untreated Col II, (b) HNE-treated Col II at a 1:200 MR, (c) HNE-treated Col II at a 1:200 MR + 0.1 mM CAR, (d) 0.1 mM CAR-treated Col II. (e) Cell viability of chondrocytes was evaluated by MTT assay. (f) Culture media from cultured cells was used to determine $\mathrm{PGE}_{2}$ and MMP-13 levels. ANOVA tests and Bonferroni's multiple comparison were performed to compare each condition. The data are means \pm SEM of $n=4$. ${ }^{*} P<0.05,{ }^{* *} P<0.01,{ }^{* * *} P<0.001$. 
was dramatically decreased thereafter when Col II was modified by HNE at a 200 MR. However, ICAM-1 expression was significantly enhanced by HNE-treated Col II at a 1:20 MR and then declined to the control level. Since Col II is a ligand for $\alpha 1 \beta 1$ integrin, we suggest that the increment of ICAM- 1 expression is $\alpha 1 \beta 1$-dependent. The involvement of $\alpha 1 \beta 1$ integrin in ICAM-1 expression was proposed by Nakayamada et al. [19], who postulated that the interaction of $\beta 1$ integrin with the ECM heightens ICAM-1 expression in synovial cells. In OA, integrin and ICAM-1 receptors play a critical role in maintaining cartilage homeostasis [20]. High ICAM- 1 and $\alpha 1 \beta 1$ integrin expression levels in the early stages of $\mathrm{OA}$ are indicated by several reports in humans and animals [20-22]. In adult joints, increased of $\beta 1$ integrin was reported in osteoarthritic monkey cartilage compared to normal cartilage [22] and in human OA samples at minimally damaged locations compared to areas with more severe lesions [23]. Knee joints of $\alpha 1 \beta 1$-null mice display precocious proteoglycans loss, cartilage erosion associated with increased MMP-2 and MMP-3 expression, and synovial hyperplasia [24,25].

Then after, we have used immunoprecipitation method to examine the possibility that FAK participates in signaling from $\alpha 1 \beta 1$ integrins after cell adhesion. We provide evidence for formation of a $\alpha 1 \beta 1$ integrin-pFAK complex in cultured chondrocytes. Moreover, we demonstrate that the phosphorylated level of FAK decreased when cells were incubated with HNE-modified Col II at a 1:200 MR. These findings support the role of FAK as intermediates in $\alpha 1 \beta 1$ integrin-dependent signaling in chondrocytes adhering to HNE-Col II adducts. Our work, interpreted in the context of what is known about focal adhesion assembly, suggests that chondrocytes adhesion to HNE-Col II adducts by $\alpha 1 \beta 1$ integrins leads to recruitment of FAK. Intracellular signaling from the ECM is mediated through major cell-surface receptors called integrins, which serve as transmembrane links between the extracellular environment and focal adhesions within the cell [26]. Interaction of integrins with the ECM at these focal adhesions leads to recruitment of several signaling molecules such as paxillin, vinculin, talin and FAK $[27,28]$ Interaction between $\beta 1$ integrin and $\mathrm{Col} \mathrm{II}$ in chondrocytes protects cells against apoptosis and mediates responses to external changes by maintaining the tissue composition and mechanical properties of articular cartilage [5].

Previous reports have demonstrated that ECM modification generates a panoply of signalling pathways implicated in various physiological and pathophysiological events [29]. To investigate this concept, we studied the possibility that HNE-modified Col II modulates catabolic and inflammatory responses known to be involved in OA through MAPK and NF- $\kappa$ B activation. Our data clearly showed that low alkylation of Col II strongly activates
ERK $^{1 / 2}$ and NF- $\kappa$ B-p65 and slightly activates p38 MAPK. However, high alkylation of Col II dramatically inhibits ERK $^{1 / 2}$ and NF- $\kappa \mathrm{B}-\mathrm{p} 65$ and strongly stimulates p38 MAPK. Collectively, our findings suggest that NF- $\kappa \mathrm{B} /$ ERK $^{1 / 2}$ and p38 kinase oppositely regulate cell viability and adhesion in the presence of HNE-Col II adducts. Integrins control cell adhesion, migration, and survival by activating complex signalling networks that involve MAPK members, such as ERK [30]. Previous studies with human chondrocytes have determined that activation of the $\beta_{1}$ integrin and subsequent ERK $K^{1 / 2}$ and NF- $\kappa \mathrm{B}$ signalling pathways is extremely important for cell differentiation and survival, and the inhibition of which can induce apoptosis [31,32]. Stupack et al. [33] suggested that "integrin-mediated death" is elicited by the cytoplasmic domain of unligated $\beta_{1}$-integrin, resulting in caspase- 8 recruitment to the cell membrane. In contrast, Wei et al. [34] found that p38 MAPK activity in chondrocytes is essential for the induction of cell death. p38 MAPK forms a complex with caspase- 8 and consequently attaches to the death-executing machinery.

Since OA is associated with cartilage degradation and synovium inflammation, we investigated the ability of HNE-Col II adducts to induce catabolic and inflammatory genes. Among them, MMP-13 and COX-2 assumed a crucial role. We found that interactions between chondrocytes and the HNE-modified matrix specifically evoked MMP-13 by low Col II alkylation and COX-2 by high Col II alkylation. These data, combined with those on signalling pathways, suggest that MMP-13 and COX2 expression depend mainly on ERK ${ }^{1 / 2}$ and p38 MAPK, respectively. It has been reported that $\mathrm{Col} I$ and fibronectin fragments induce MMP-13 expression in chondrocytes through ERK ${ }^{1 / 2}$ signalling via $\alpha 1 \beta 1$ and $\alpha \mathrm{v} \beta 3$ integrin, respectively $[5,35,36]$. However, it has been observed that integrin-mediated adhesion to ECM proteins induces de COX-2 synthesis involving signalling through the p38 MAPK pathway [37]. The role of AGEmodified proteins in OA has been demonstrated in previous studies. It has been found that AGEs significantly stimulate a panoply of signalling pathways-mediating MMP-1, -3, and -13 expression [38-40]. These responses occur through receptors for AGEs, implicating those engaged in catabolic and inflammatory processes in OA.

Finally, we tested the hypothesis that CAR treatment is capable of inhibiting HNE-Col II adduct-induced changes in cell morphology and function. The data revealed that $0.1 \mathrm{mM}$ CAR prevents changes in cell morphology and viability and blocked the production of factors known to be involved in OA, such as MMP-13 and $\mathrm{PGE}_{2}$. CAR exerts its effect in a dose-dependent manner with the maximum at $0.1 \mathrm{mM}$ (data not shown). CAR was previously found to directly trap HNE [41]. By trapping HNE in stable covalent adducts, CAR 
can inhibit HNE-induced protein cross-linking. Therefore, it has the ability to displace bound HNE off the protein surface or to bind covalently into HNE-protein adducts. It is noteworthy that CAR can be covalently incorporated into glycated proteins, and consequently reduce protein carbonyl content [42]. In addition, CAR has been observed to reverse the physicochemical changes of proteins induced by glycation [43]. CAR, a dipeptide (b-alanyl-L-histidine), is considered to be a natural antioxidant and antiglycating agent that suppresses protein modifications by AGEs and LPO products $[44,45]$. It may play an important part as an antiaging molecule, since it can delay senescence in cultured fibroblasts and reverse the senescent phenotype in cultured human cells [46]. Furthermore, it is useful in preventing several diseases, as beautifully depicted in a recent, dedicated review [47].

\section{Conclusions}

Collectively, we presented evidence that Col II modification by HNE is capable of inducing changes in chondrocyte phenotype and function. Our results clearly showed that interactions between chondrocytes and HNE-Col II adducts, probably via adhesion molecules, strongly evoking a panoply of signalling pathways that trigger cell adhesion and viability as well as MMP-13 and COX-2 expression, as illustrated in Figure 7. The fact that HNE-Col II adducts elicited cell death and catabolic and inflammatory responses suggested their involvement in OA. CAR has been found to prevent the effects of

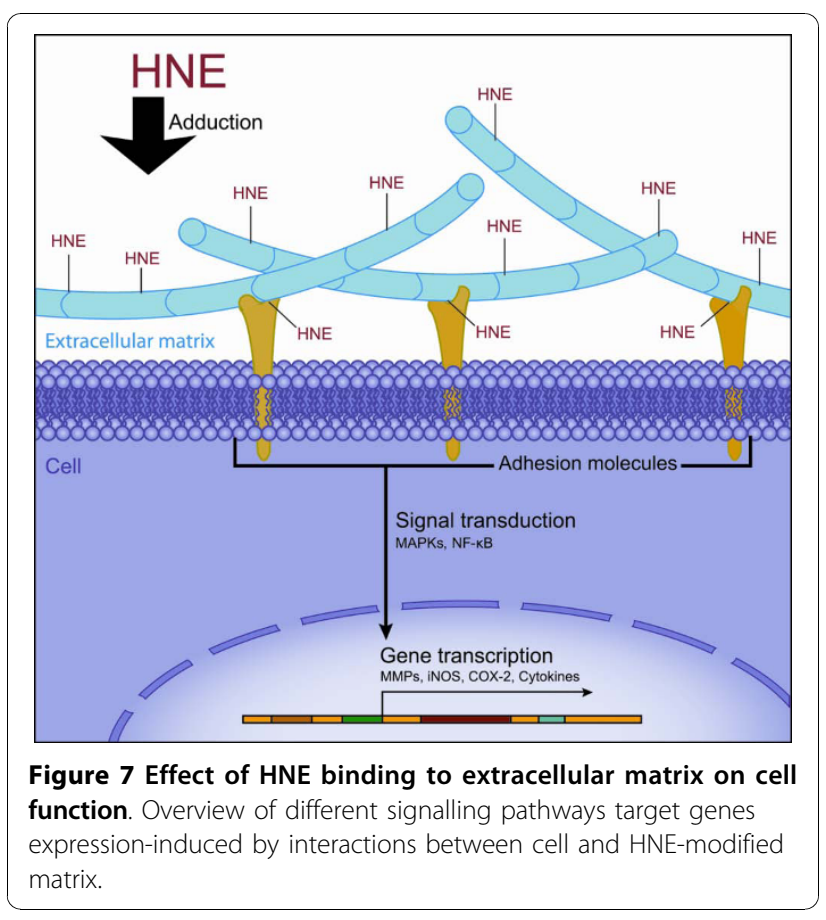

HNE-Col II adducts, although the mechanism of action has not yet been elucidated. Further research is required to understand the implication of Col II modification by HNE and other ECM components in OA as well as the potential of HNE-trapping drugs in OA.

\section{Abbreviations}

CAR: carnosine; Col II: Type II collagen; COX-2: cyclooxygenase-2, FAK: focal adhesion kinase; HNE: hydroxynonenal; ICAM-1: intercellular signal-regulated molecule-1; LPO; lipid peroxidation; MAPK: mitogen-activated protein kinases; MMPs: matrix metalloproteinases; NF- $\kappa$ B: nuclear factor-kappa $\mathrm{B} ; \mathrm{OA}$ : osteoarthritis, $\mathrm{PGE}_{2}$ : prostaglandin $\mathrm{E} 2$.

\section{Acknowledgements}

This study was supported by the Canadian Institutes of Health Research (CIHR Grant \# IMH-90112).

\section{Authors' contributions}

REB performed the experimental study, contributed to preparation of the manuscript and undertook the statistical analysis. QS assisted in the experiments and in the isolation of chondrocytes from human cartilage. YM and LM performed confocal microscopy studies and MW performed flow cytometry analysis. JFC, HF, MDB, KM and JCF evaluated and interpreted the data and assisted with preparation of the manuscript. MB designed the study, supervised the project, evaluated and interpreted the data, and prepared the manuscript. All authors read and approved the final manuscript.

\section{Author information}

Dr. M Benderdour is a research scholar of the FRSQ. J-F Côté holds a CIHR New Investigator award.

\section{Competing interests}

The authors declare that they have no competing interests.

Received: 11 February 2010 Revised: 13 August 2010

Accepted: 26 October 2010 Published: 26 October 2010

\section{References}

1. Xu J, Wang W, Clark CC, Brighton CT: Signal transduction in electrically stimulated articular chondrocytes involves translocation of extracellular calcium through voltage-gated channels. Osteoarthritis Cartilage 2009, 17:397-405.

2. von der Mark K, Gauss V, von der Mark H, Müller P: Relationship between cell shape and type of collagen synthesised as chondrocytes lose their cartilage phenotype in culture. Nature 1977, 267:531-532.

3. Mollenhauer J, Mok MT, King KB, Gupta M, Chubinskaya S, Koepp H, Cole AA: Expression of anchorin CII (cartilage annexin V) in human young, normal adult, and osteoarthritic cartilage. J Histochem Cytochem 1999, 47:209-220.

4. Knudson W, Aguiar DJ, Hua Q, Knudson CB: CD44-anchored hyaluronanrich pericellular matrices: an ultrastructural and biochemical analysis. Exp Cell Res 1996, 228:216-228.

5. Loeser RF: Integrins and cell signaling in chondrocytes. Biorheology 2002, 39:119-124.

6. Hamerman D: The biology of osteoarthritis. N Engl J Med 1989, 320:1322-1330.

7. Hollander AP, Pidoux I, Reiner A, Rorabeck C, Bourne R, Poole AR: Damage to type II collagen in aging and osteoarthritis starts at the articular surface, originates around chondrocytes, and extends into the cartilage with progressive degeneration. J Clin Invest 1995, 96:2859-2869.

8. Dean DD: Proteinase-mediated cartilage degradation in osteoarthritis. Semin Arthritis Rheum 1991, 20:2-11.

9. Shah R, Raska K Jr, Tiku ML: The presence of molecular markers of in vivo lipid peroxidation in osteoarthritic cartilage: a pathogenic role in osteoarthritis. Arthritis Rheum 2005, 52:2799-2807.

10. Morquette B, Shi Q, Lavigne P, Ranger P, Fernandes JC, Benderdour M: Production of lipid peroxidation products in osteoarthritic tissues: new 
evidence linking 4-hydroxynonenal to cartilage degradation. Arthritis Rheum 2006, 54:271-281.

11. Vaillancourt F, Morquette B, Shi Q, Fahmi H, Lavigne P, Di Battista JA, Fernandes JC, Benderdour M: Differential regulation of cyclooxygenase-2 and inducible nitric oxide synthase by 4-hydroxynonenal in human osteoarthritic chondrocytes through ATF-2/CREB-1 transactivation and concomitant inhibition of NF-kappaB signaling cascade. J Cell Biochem 2007, 100:1217-1231.

12. Shi Q, Vaillancourt F, Cote V, Fahmi $H$, Lavigne $P$, Afif $H$, Di Battista JA, Fernandes JC, Benderdour M: Alterations of metabolic activity in human osteoarthritic osteoblasts by lipid peroxidation end product 4hydroxynonenal. Arthritis Res Ther 2006, 8:R159.

13. Poli G, Schaur RJ, Siems WG, Leonarduzzi G: 4-Hydroxynonenal: A membrane lipid oxidation product of medicinal interest. Med Res Rev 2008, 28:569-631.

14. Tiku ML, Shah R, Allison GT: Evidence linking chondrocyte lipid peroxidation to cartilage matrix protein degradation. Possible role in cartilage aging and the pathogenesis of osteoarthritis. J Biol Chem 2000 275:20069-20076.

15. Altman R, Asch E, Bloch D, Bole G, Borenstein D, Brandt K, Christy W, Cooke TD, Greenwald R, Hochberg M: Development of criteria for the classification and reporting of osteoarthritis. Classification of osteoarthritis of the knee. Diagnostic and Therapeutic Criteria Committee of the American Rheumatism Association. Arthritis Rheum 1986, 29:1039-1049.

16. Mosmann T: Rapid colorimetric assay for cellular growth and survival: application to proliferation and cytotoxicity assays. J Immunol Methods 1983, 65:55-63.

17. Paul RG, Bailey AJ: The effect of advanced glycation end-product formation upon cell-matrix interactions. Int J Biochem Cell Biol 1999, 31:653-660.

18. Rittie L, Monboisse JC, Gorisse MC, Gillery P: Malondialdehyde binding to proteins dramatically alters fibroblast functions. J Cell Physiol 2002, 191:227-236.

19. Nakayamada S, Saito K, Fujii K, Yasuda M, Tamura M, Tanaka Y: beta1 integrin-mediated signaling induces intercellular adhesion molecule 1 and Fas on rheumatoid synovial cells and Fas-mediated apoptosis. Arthritis Rheum 2003, 48:1239-1248.

20. Knudson W, Loeser RF: CD44 and integrin matrix receptors participate in cartilage homeostasis. Cell Mol Life Sci 2002, 59:36-44.

21. Lapadula G, lannone F, Zuccaro C, Grattagliano V, Covelli M, Patella V, Lo BG, Pipitone V: Integrin expression on chondrocytes: correlations with the degree of cartilage damage in human osteoarthritis. Clin Exp Rheumatol 1997, 15:247-254.

22. Loeser RF, Carlson CS, McGee MP: Expression of beta 1 integrins by cultured articular chondrocytes and in osteoarthritic cartilage. Exp Cell Res 1995, 217:248-257.

23. Lapadula G, lannone F, Zuccaro C, Grattagliano V, Covelli M, Patella V, Lo BG, Pipitone V: Chondrocyte phenotyping in human osteoarthritis. Clin Rheumatol 1998, 17:99-104.

24. Zemmyo M, Meharra EJ, Kuhn K, Creighton-Achermann L, Lotz M: Accelerated, aging-dependent development of osteoarthritis in alpha1 integrin-deficient mice. Arthritis Rheum 2003, 48:2873-2880.

25. Raducanu A, Hunziker EB, Drosse I, Aszodi A: Beta1 integrin deficiency results in multiple abnormalities of the knee joint. J Biol Chem 2009, 284:23780-23792.

26. Hynes RO: Integrins: a family of cell surface receptors. Cell 1987, 48:549-554.

27. Park MS, Kim YH, Lee JW: FAK mediates signal crosstalk between type II collagen and TGF-beta 1 cascades in chondrocytic cells. Matrix Biol 2010, 29:135-142.

28. Takahashi I, Onodera K, Sasano Y, Mizoguchi I, Bae JW, Mitani H, Kagayama M, Mitani H: Effect of stretching on gene expression of beta1 integrin and focal adhesion kinase and on chondrogenesis through cellextracellular matrix interactions. Eur J Cell Biol 2003, 82:182-192.

29. Rees MD, Kennett EC, Whitelock JM, Davies MJ: Oxidative damage to extracellular matrix and its role in human pathologies. Free Radic Biol Med 2008, 44:1973-2001.

30. Mitra SK, Hanson DA, Schlaepfer DD: Focal adhesion kinase: in command and control of cell motility. Nat Rev Mol Cell Biol 2005, 6:56-68.
31. Shakibaei M, Schulze-Tanzil G, De SP, John T, Rahmanzadeh M, Rahmanzadeh R, Merker HJ: Inhibition of mitogen-activated protein kinase kinase induces apoptosis of human chondrocytes. J Biol Chem 2001, 276:13289-13294.

32. Wu S, Flint JK, Rezvani G, De Luca F: Nuclear factor-kappaB p65 facilitates longitudinal bone growth by inducing growth plate chondrocyte proliferation and differentiation and by preventing apoptosis. $J$ Bio Chem 2007, 282:33698-33706.

33. Stupack DG, Puente XS, Boutsaboualoy S, Storgard CM, Cheresh DA: Apoptosis of adherent cells by recruitment of caspase-8 to unligated integrins. J Cell Biol 2001, 155:459-470.

34. Wei L, Sun XJ, Wang Z, Chen Q: CD95-induced osteoarthritic chondrocyte apoptosis and necrosis: dependency on p38 mitogen-activated protein kinase. Arthritis Res Ther 2006, 8:R37.

35. Ronziere MC, Aubert-Foucher E, Gouttenoire J, Bernaud J, Herbage D, Mallein-Gerin F: Integrin alpha1 beta1 mediates collagen induction of MMP-13 expression in MC615 chondrocytes. Biochim Biophys Acta 2005, 1746:55-64.

36. Forsyth $C B$, Pulai J, Loeser RF: Fibronectin fragments and blocking antibodies to alpha2beta1 and alpha5beta1 integrins stimulate mitogenactivated protein kinase signaling and increase collagenase 3 (matrix metalloproteinase 13) production by human articular chondrocytes. Arthritis Rheum 2002, 46:2368-2376.

37. Viji Rl, Kumar VB, Kiran MS, Sudhakaran PR: Modulation of cyclooxygenase in endothelial cells by fibronectin: relevance to angiogenesis. J Cell Biochem 2008, 105:158-166.

38. Nah SS, Choi IY, Yoo B, Kim YG, Moon HB, Lee CK: Advanced glycation end products increases matrix metalloproteinase-1, -3 , and -13 , and TNF-alpha in human osteoarthritic chondrocytes. FEBS Lett 2007, 581:1928-1932.

39. Loeser RF, Yammani RR, Carlson CS, Chen H, Cole A, Im HJ, Bursch LS, Yan SD: Articular chondrocytes express the receptor for advanced glycation end products: Potential role in osteoarthritis. Arthritis Rheum 2005, 52:2376-2385.

40. Yammani RR, Carlson CS, Bresnick AR, Loeser RF: Increase in production of matrix metalloproteinase 13 by human articular chondrocytes due to stimulation with S100A4: Role of the receptor for advanced glycation end products. Arthritis Rheum 2006, 54:2901-2911.

41. Liu Y, Xu G, Sayre LM: Carnosine inhibits (E)-4-hydroxy-2-nonenal-induced protein cross-linking: structural characterization of carnosine-HNE adducts. Chem Res Toxicol 2003, 16:1589-1597.

42. Brownson C, Hipkiss AR: Carnosine reacts with a glycated protein. Free Radic Biol Med 2000, 28:1564-1570.

43. Yeargans GS, Seidler NW: Carnosine promotes the heat denaturation of glycated protein. Biochem Biophys Res Commun 2003, 300:75-80.

44. Price DL, Rhett PM, Thorpe SR, Baynes JW: Chelating activity of advanced glycation end-product inhibitors. J Biol Chem 2001, 276:48967-48972.

45. Aldini G, Facino RM, Beretta G, Carini M: Carnosine and related dipeptides as quenchers of reactive carbonyl species: from structural studies to therapeutic perspectives. Biofactors 2005, 24:77-87.

46. Hipkiss AR: On the enigma of carnosine's anti-ageing actions. Exp Gerontol 2009, 44:237-242.

47. Hipkiss AR: Chapter 3 carnosine and its possible roles in nutrition and health. Adv Food Nutr Res 2009, 57:87-154.

\section{doi:10.1186/ar3173}

Cite this article as: El-Bikai et al.: Perturbation of adhesion moleculemediated chondrocyte-matrix interactions by 4 -hydroxynonenal binding: implication in osteoarthritis pathogenesis. Arthritis Research \& Therapy 2010 12:R201. 